\title{
Obesity/overweight and asthma control in LEBANESE adults: a cross-sectional study
}

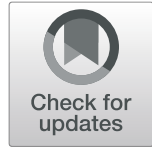

Carla Irani ${ }^{1,2^{*}}$, Salim Adib ${ }^{3}$, Georges Halaby ${ }^{4}$ and Abla Sibai ${ }^{3}$

\begin{abstract}
Background: Studies exploring the association between weight and asthma are not conclusive. Both obesity and asthma have been increasing in Lebanon, their association is not yet documented. The aim of this study is to explore the effect of weight on asthma control in adults.

Methods: This is a cross-sectional study, involving all consecutive asthma patients presenting to the outpatient allergy clinic at the Hotel-Dieu de France (HDF) University Hospital between January 1, 2014 and December 30, 2016. Patients included were those who consented to fill the Asthma Control Test (ACT) after 3 months of therapy. $\mathrm{BMI}$ was reported at the same time of the questionnaire.

Results: A total of 183 records of diagnosed asthma cases in adults were included. Sixty-three (34.4\%) were males and $120(65.6 \%)$ females, with a mean age of 38.5 (SD = 14.3). Ninety patients (49.2\%) were of normal weight, 65 (35.5\%) overweight and 28 (15.3\%) obese. Seventy-one percent had an ACT score $\leq 19$, which corresponds to poor asthma control. Patients who were overweight or obese were more likely to have poor asthma control compared to patients who had a normal weight at the time of evaluation.

Conclusion: In conclusion, our study showed a significant association between asthma control as assessed by the $\mathrm{ACT}$ and high BMl defining overweight or obesity. This is the first national study exploring the association between asthma and overweight/obesity in Lebanon. A larger study with sampling from different specialists' sites is needed to draw more conclusions about this association.
\end{abstract}

Keywords: Asthma control test, Obesity/overweight, Asthma

\section{Background}

Asthma in adulthood is an increasingly detected respiratory disease, the control of which is often affected by various factors, including overweight. The association between weight and asthma control in adults has been based mostly on observational studies, and solid evidence is still needed. In Lebanon, obesity and asthma have been increasing but the actual concomitance of both health problems is not yet documented, while the negative impact of obesity on other chronic diseases such as diabetes and coronary vascular diseases has already been reported $[1,2]$.

\footnotetext{
* Correspondence: iranica@yahoo.com

${ }^{1}$ Internal Medicine \& Clinical Immunology Department, Hotel Dieu de France hospital, St Joseph University, Blvd A. Naccache, Beirut 166830, Lebanon ${ }^{2}$ Division of Pulmonary Medicine, University of Alberta hospital, Alberta, Canada

Full list of author information is available at the end of the article
}

The prevalence of asthma in Lebanese adults, expressed as the prevalence of hyper-reactive airways is estimated at 9\% [3]. While effective asthma treatment is available, a meta-analysis including 300 million patients found that $20 \%$ of patients worldwide had severe illness despite adequate treatment [4]. The "Asthma Insights and Reality" study in Lebanon showed that about $20 \%$ of hospitalized patients had poorly controlled asthma [5]. The severity of asthma is usually classified according to the Global Initiative for Asthma (GINA) guidelines [6] as "controlled", "partially controlled" or "uncontrolled", based on detailed clinical definition. In observational studies, the contribution of overweight / obesity to the severity of asthma drew the attention of researchers. The prevalence of obesity in Lebanon is increasing: in 2009, the STEPS survey reported obesity in $26.1 \%$ of adults [7]. In 2008, the US National Asthma Survey suggested that obesity is associated with several measures of asthma severity and poor control, 
including symptoms, missed work days, medication use and GINA severity classification in adults [8]. Findings regarding the association between obesity and asthma control are not consistent. For example, it appears that the vulnerability of obese patients may vary with the allergic or non-allergic etiology of their asthma [9]. Some studies reject any potential link between Body Mass Index (BMI) and asthma control, and show that poorly controlled asthma may be associated with several socio-demographic factors [10]. The aim of this study is to explore the effect of weight on asthma control in adults in Lebanon.

A conceptual model is presented below to illustrate the research questions. Figure 1.

\section{Methods}

This is a cross-sectional study involving all consecutive asthma patients presenting to the outpatient allergy clinic at the Hotel-Dieu de France (HDF) University Hospital between January 1, 2014 and December 30, 2016. Patients included were those who consented to fill a questionnaire evaluating disease control (Asthma Control Test: ACT) after 3 months of therapy. BMI was calculated after recording weight and height given by the patient when completing the questionnaire.

All included patients were 18 years of age and older when formally diagnosed with asthma according to the GINA classification, and followed-up exclusively at the HDF allergy clinic between January 1, 2014 and December 30, 2016. All participants should have received the same standard treatments as defined by the GINA guidelines [6]. The control of their asthma was evaluated within 3 months after the prescription of the treatment. According to the GINA guidelines, a clinical evaluation is done every
3 months to decide whether to step-up or step-down therapy. Patients were excluded if they presented with heavy co-morbidities: cancer, lupus or vasculitis diseases, congenital or acquired immunodeficiency, or chronic obstructive respiratory disease (COPD) ( $2 \%$ of the crosssectional sample).

Overweight and obesity were defined using the Body Mass Index (BMI), as per the CDC standard definition [11]. Overweight represents a BMI of $>=25 \mathrm{~kg} / \mathrm{m}^{2}$ and obese is a BMI $>30 \mathrm{~kg} / \mathrm{m}^{2}$. Lower BMIs represent "normal weight".

The outcome of interest was "asthma control" measured with the Asthma Control Test (ACT) that is specifically conceived to assess the level of asthma control in patients treated according to the GINA guidelines (GINA 2015) [12]. The ACT is a 5-item self-administered questionnaire previously validated in Arabic [13]. The sum of answers ranges from 5 to 25 , with higher scores reflecting better asthma control. These scores are divided as follows: "uncontrolled" (scores 5-19) or "controlled" (20-24) asthma. The score of 25 indicates an optimal level of control [14]. For the purposes of this analysis, patients with an optimal score were included in the "controlled" group. Control variables belonged to 2 categories:

a. Socio-demographic factors: age ( $\leq 45$ and $>45$ years old); gender; level of education (2 categories: undergraduate, post-graduate)

b. Health-related factors: Tobacco use (2 categories: none ever, past/current smokers for tobacco and/or waterpipe); compliance with treatment (yes/no), history of allergic sensitization (measured by skintest or specific respiratory IgE assay); history of childhood asthma (yes/no)

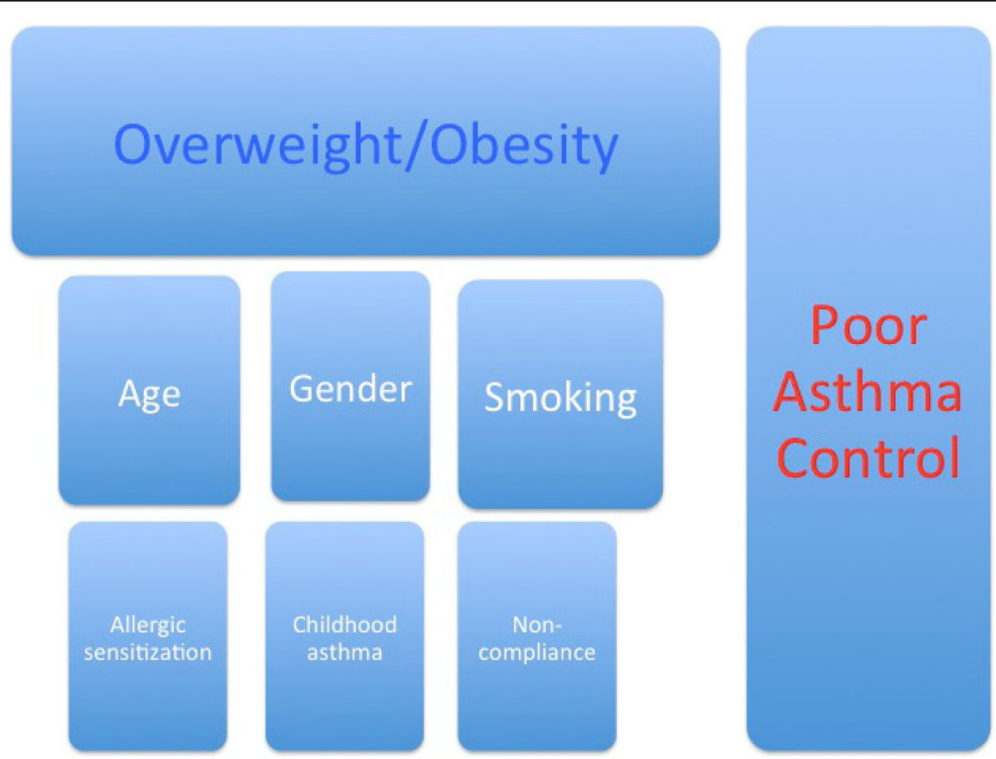

Fig. 1 Conceptual model. A conceptual framework linking Asthma control to Overweight/Obesity in presence of possible confounders 


\section{Statistical analysis}

Data analysis was performed on SPSS software version 23. A descriptive analysis was done using the counts and percentages for categorical variables and mean and standard deviation for continuous measures. The Student t-test was used to compare the means of continuous variables between two groups. For comparison between categorical variables, the chi-square and Fisher exact tests were used. Two backward logistic regressions were conducted, taking the good vs poor asthma control as the dependent variable and taking the BMI as a continuous variable in the first regression and taking it as a categorical variable in the second regression. All other variables that showed a $p<0.2$ in the bivariate analysis were also taken as independent variables in the multivariable analysis models. A $P$-value less than 0.05 was considered significant in all cases.

\section{Ethical considerations}

The project was approved by the Hotel-Dieu de France (HDF), St Joseph University ethical committee and the IRB committee at the American University of Beirut (AUB). The medical records examined were kept in a private storage area, and the chart review was done confidentially. Informed consent to contribute to research is a routine procedure at HDF, and only data from those who signed a consent were included.

\section{Results}

A total of 183 records of diagnosed asthma cases in adults were available for analysis during the study period. Of those, 63 (34.4\%) were males and 120 (65.6\%) females, with a mean age of $38.5(\mathrm{SD}=14.3)$. Based on the BMI, 90 (49.2\%) patients were of normal weight at the time of evaluation of control by ACT, 65 (35.5\%) were overweight and $28(15.3 \%)$ were obese. For the analysis, we combined the overweight and obese. Only $13.1 \%$ were current smokers, and $76.5 \%$ had graduate or postgraduate degrees. Allergic sensitization was present in $79.2 \%$ of cases, and $68.3 \%$ did not report any childhood asthma. (Table 1).

\section{Bivariate analysis}

The results of the bivariate analysis, taking good vs poor asthma control as the dependent variable, showed that a significantly higher mean BMI was found in patients with a poor asthma control compared to those with a good asthma control (26.37 vs 24.03), whereas a significantly higher percentage of patients who were compliant to treatment had good asthma control compared to those who were non-compliant to treatment $(66.04 \%$ vs 46.15\%).

When dividing the BMI into categories, a significantly higher percentage of patients who had a normal BMI had good asthma control (78.8\% vs $36.9 \%)$, whereas a
Table 1 Sociodemographic and other characteristics of participants

\begin{tabular}{|c|c|}
\hline Variables & $\begin{array}{l}\text { Total } \\
N=183 \\
\mathrm{n}(\%)\end{array}$ \\
\hline \multicolumn{2}{|l|}{ Age } \\
\hline $18-45$ & $110(60.10)$ \\
\hline$>45$ & $73(39.9)$ \\
\hline \multicolumn{2}{|l|}{ Gender } \\
\hline Females & $120(65.57)$ \\
\hline Males & $63(34.42)$ \\
\hline Graduate studies* (yes) & $135(73.77)$ \\
\hline \multicolumn{2}{|l|}{ Health related characteristics } \\
\hline Allergic sensitization** (yes) & $147(80.32)$ \\
\hline Childhood asthma (yes) & $58(31.69)$ \\
\hline Smoking status (cigarettes or waterpipe (Yes) & $41(22.40)$ \\
\hline Compliance with treatment^ (yes) & $117(63.93)$ \\
\hline \multicolumn{2}{|l|}{ Clinical Profile } \\
\hline \multicolumn{2}{|l|}{ Body Mass Index (BMI) categories } \\
\hline Normal weight $(\mathrm{BMl}<25)$ & $90(49.2)$ \\
\hline Overweight $(25 \leq \mathrm{BMI}<30)$ & $65(35.5)$ \\
\hline Obese (BMI $\geq 30$ ) & $28(15.3)$ \\
\hline
\end{tabular}

higher percentage of patients who were overweight (43.8\% vs $15.4 \%)$ or obese $(19.2 \%$ vs $5.8 \%)$ had poor asthma control (Table 2).

\section{Mutlivariable analysis}

The results of a first logistic regression taking the good vs poor* asthma control as the dependent variable and taking the body mass index as a continuous variable, showed that a higher BMI $(\mathrm{ORa}=0.839)$ was significantly associated with a poor asthma control. In addition, females $(\mathrm{ORa}=0.531)$ had a poorer asthma control compared to their male counterparts, whereas being compliant to treatment $(\mathrm{ORa}=1.848)$ was associated with a good asthma control (with the last two associations tending to significance) (Table 3, Model 1).

A second logistic regression taking the good vs poor asthma control as the dependent variable and taking the body mass index as a categorical variable, showed that being overweight (BMI between 25 and less than 30$)(\mathrm{ORa}=$ $0.155)$ or obese $(\mathrm{BMI} \geq 30)(\mathrm{ORa}=0.131)$ compared to a normal BMI were associated with a poor asthma control. Being compliant to treatment $(\mathrm{ORa}=1.882)$ was associated with a good asthma control, with this association tending to significance $(p=0.087)$ (Table 3, Model 2). 
Table 2 Bivariate analysis of the outcome "Poor Asthma Control" with covariates

\begin{tabular}{|c|c|c|c|}
\hline Variables & $\begin{array}{l}\text { Poor Asthma } \\
\text { Control } \\
\text { ACT } \leq 19 \\
n=130\end{array}$ & $\begin{array}{l}\text { Good Asthma } \\
\text { Control } \\
\text { ACT>19 } \\
n=53\end{array}$ & $p$-value* \\
\hline \multicolumn{4}{|l|}{ Age category } \\
\hline$\leq 45$ years old & $88(67.69)$ & $42(32.31)$ & \multirow[t]{2}{*}{0.193} \\
\hline$>45$ years old & $41(77.36)$ & $12(22.64)$ & \\
\hline \multicolumn{4}{|l|}{ Gender } \\
\hline Females & $90(69.23)$ & $30(56.6)$ & \multirow[t]{2}{*}{0.103} \\
\hline Males & $40(30.77)$ & $23(43.44)$ & \\
\hline Body Mass Index (continuous variable) & $26.37 \pm 3.94$ & $24.03 \pm 3.21$ & $<0.001$ \\
\hline \multicolumn{3}{|l|}{ Body Mass Index categories } & \multirow[t]{4}{*}{$<0.001$} \\
\hline Normal $(\mathrm{BMI}<25)$ & $48(36.9 \%)$ & $41(78.8 \%)$ & \\
\hline Overweight $(25 \leq \mathrm{BMI}<30)$ & $57(43.8 \%)$ & $8(15.4 \%)$ & \\
\hline Obese (BMI $\geq 30$ ) & $25(19.2 \%)$ & $3(5.8 \%)$ & \\
\hline Graduate studies (yes) & $88(67.69)$ & $37(69.81)$ & 0.286 \\
\hline Allergy (yes) & $102(79.07)$ & $44(83.02)$ & 0.486 \\
\hline Childhood asthma (yes) & $41(31.54)$ & $17(32.08)$ & 0.944 \\
\hline Smoking (yes) & $31(23.85)$ & $10(18.87)$ & 0.184 \\
\hline Compliance (yes) & $60(46.15)$ & $35(66.04)$ & 0.015 \\
\hline
\end{tabular}

*Numbers in bold indicate significant $p$-values

\section{Discussion}

Increased BMI has been associated with poor asthma control in multiple studies, yet the association is complex and conflicting results are shown in different studies. The effect of age on poor asthma control in adults have shown that older age is usually associated with more severe asthma and poorer control because of the presence of other comorbidities. This was not the case in our study where younger age $\leq 45$ had poorer disease control compared to older age. This may have been due to a selection bias since the mean age of our population is 38.5. This is most likely due to the fact that the population is selected from an allergy clinic where the population is in general younger. Indeed, in our study $80 \%$ of the patients showed aeroallergen sensitization, which is as well a selection bias. Allergic sensitization was not significantly associated with higher BMI or poorer asthma control: in both controlled and uncontrolled asthmatics, the percentage of allergic patients was much higher than the non-allergic. As far as gender, studies have shown that females are more likely to have poor disease control compared to males [15]. In our study, we had a higher percentage of females $(65.57 \%)$ than males. Even though their association with poor asthma control was almost significant with females being more likely to have poorer control than males, the

Table 3 Multivariable analysis

\begin{tabular}{|c|c|c|c|c|}
\hline Variable & $p$-value & Adjusted odds ratio & \multicolumn{2}{|c|}{ 95\% Confidence Interval } \\
\hline \multicolumn{5}{|c|}{$\begin{array}{l}\text { Model 1: Logistic regression taking the good vs poor asthma control as the dependent variable and taking the body mass index as a continuous } \\
\text { variable. }\end{array}$} \\
\hline Gender (males ${ }^{\mathrm{a}}$ vs females) & 0.078 & 0.531 & 0.263 & 1.074 \\
\hline Body Mass Index & 0.001 & 0.839 & 0.756 & 0.930 \\
\hline Compliance to treatment (no ${ }^{a}$ vs yes) & 0.085 & 1.848 & 0.919 & 3.714 \\
\hline \multicolumn{5}{|c|}{$\begin{array}{l}\text { Model 2: Logistic regression taking the good vs poor asthma control as the dependent variable and taking the body mass index as a categorical } \\
\text { variable. }\end{array}$} \\
\hline Compliance to treatment (no ${ }^{a}$ vs yes) & 0.087 & 1.882 & 0.912 & 3.884 \\
\hline Body Mass Index overweight category compared to normal & $<0.001$ & 0.155 & 0.062 & 0.389 \\
\hline Body Mass Index obese category compared to normal & 0.002 & 0.131 & 0.035 & 0.485 \\
\hline
\end{tabular}

${ }^{a}$ Reference group

Variables entered in Model 1: age, gender, compliance to treatment, Body Mass Index

Variables entered in Model 2: age, gender, compliance to treatment, Body Mass Index categories 
association with higher BMI was not statistically significant; indeed, we had almost the same number of female patients being of normal weight or overweight/obese. In the western world, it seems that females are more likely to be overweight [16]. Generally, this is not true in Lebanon where females are more concerned about their weight and body image [17]. Gender did not significantly affect the association between poor asthma control and BMI. The association with higher BMI was significant, where patients who have a graduate or postgraduate degree are more likely to have a higher BMI compared to patients who were undergraduates, but this association is still being studied to further strengthen this notion [18]. The association between graduate studies and poor asthma control was barely significant in the bivariate analysis of this study, even though almost $68 \%$ of patients who had graduate or postgraduate degrees, had poor asthma control as defined by the ACT. The presence of childhood asthma is not, in general, a risk factor for poor disease control in adulthood. There are no conclusive studies showing that the history of childhood asthma is associated with poor disease control in adults. Conversely, few studies have shown that a patient with a history of childhood asthma may be more aware of asthma management and therefore better controlled. Recent pediatric asthma guidelines include inhaled rather than oral corticosteroids for childhood asthma, therefore limiting the effect of treatment-induced weight gain in asthmatic. Our study showed no significant association between the history of childhood asthma with neither higher BMI nor poor asthma control. In our study, only $22 \%$ of our patients were cigarette or waterpipe smokers. This is a main selection bias and does not reflect the prevalence of cigarette or waterpipe smokers among the Lebanese population. One possible explanation may be that since we have a higher percentage of uncontrolled asthmatics, those prefers to avoid smoking since it will worsen their respiratory symptoms and exacerbate their asthma, although studies showed that allergic or asthmatic patients do not avoid smoking [19]. In our study, smoking was not associated with higher BMI, neither with poor asthma control. Again this may be due to a low percentage of smokers among our population. A study we previously conducted to explore the effect of parental smoking on asthma exacerbation of their children showed that only $28 \%$ of parents were smokers [20]

Adherence to asthma therapy is the subject of numerous publications in developed countries [21]. In general, adherence to therapy may vary across cultures but it is a fact that non-compliance to therapy is associated with poor asthma control [22]. Therefore, medical authorities in developed countries devote a lot of resources on asthma education in an attempt to overcome the factors associated with non- adherence. Among those factors are: patients' beliefs and goals, lack of time given by physicians to explain and supervise inhaler techniques, economic problems and much more. Social desirability bias should be taken into account, because the treating physician or his clinic assistant assessed adherence to therapy. In our study, compliance was found to be present in approximately $64 \%$ of cases; there was no association with higher BMI, but it seemed that noncompliant patients have poor asthma control.

This study has several limitations. First, it is crosssectional, thereby introducing a potential selection bias. Another limitation of this study design is that it can investigate an association between overweight/obesity and poor asthma control but it cannot prove causal mechanisms. Since the study population is from a single allergy clinic, this may lead to selection bias. However, clinical information was collected at the time of the clinic visit, thus reducing recall bias. The last limitation is the fact that the follow-up was done at 3 months after the initiation or the adjustment of the therapy, our plan is to extend the follow-up over a longer period.

\section{Conclusion}

In conclusion, our study showed a significant association between poor asthma control as assessed by the Asthma Control Test and high BMI defining overweight or obesity. A larger study with sampling from different specialists' sites is needed to draw more conclusions about this association.

\section{Abbreviations}

ACT: Asthma Control Test; AUB: American University of Beirut; BMI: Body Mass Index; CDC: Centers for Disease Control; GINA: Global Initiative on Asthma; HDF: Hotel Dieu de France

\section{Acknowledgements}

Not applicable.

\section{Authors' contributions}

All listed authors contributed to the achievement of the manuscript according to the authorship guidelines. Carla Irani: Cl: data collection, writing of the manuscript, statistical analysis. Salim Adib: SA: continuous evaluation and correction, advise for structure of the study, statistical analysis support. Georges Halaby GH: support in litterature review. Abla Sibai AS: Major support in study design, continuous evaluation and correction, satistical analysis support. All authors have read and approved the manuscript.

\section{Funding \\ The study was self-funded.}

\section{Availability of data and materials}

"The datasets used and/or analysed during the current study available from the corresponding author on reasonable request."

\section{Ethics approval and consent to participate}

The study recieved approval from the IRB at AUB and ethical committe of Hotel Dieu de France hospital, St Joseph university.

Patients signed an informed consent when they filled the Asthma control test questionnaire.

Consent for publication

Consent to publish patient data is Not applicable. 


\section{Competing interests}

The authors have no competing interests.

\section{Author details}

'Internal Medicine \& Clinical Immunology Department, Hotel Dieu de France hospital, St Joseph University, Blvd A. Naccache, Beirut 166830, Lebanon. ${ }^{2}$ Division of Pulmonary Medicine, University of Alberta hospital, Alberta, Canada. ${ }^{3}$ Faculty of Health Sciences, American University of Beirut, Beirut, Lebanon. ${ }^{4}$ Endocrinology Department, Hotel-Dieu de France, St Joseph University Beirut, Beirut, Lebanon.

Received: 13 December 2018 Accepted: 5 June 2019

Published online: 17 June 2019

\section{References}

1. Sibai AM, Hwalla N, Adra N, Rahal N. Prevalence and covariates of obesity in Lebanon: findings from the first epidemiologic study. Obes Res. 2003;11: 1353-61.

2. Mallat S, Geagea G, Jurjus R A, Rizkallah A, Oueidat D, Matar et al. Obesity in Lebanon: A National Problem. World Journal of Cardiovascular Diseases, 2016, 6, 166-174.

3. Salamé J, Tyan P, Salameh P, Waked M. Hyperreactive airway disease in adults: data from a national study in Lebanon. J Med Liban. 2014;62(3): 143-9.

4. Peters P, Ferguson G, Deniz Y, Reisner C. Uncontrolled asthma: a review of the prevalence, disease burden and options for treatment. Respir Med. 2006;100:1139-51.

5. Bahous B, Soriano JB. Asthma control in Lebanon the asthma insights and reality in Lebanon. J Med Liban. 2010;58(4):204-9.

6. Reddel HK, Bateman ED, Becker A, Boulet LP, Cruz AA, Drazen JM, et al. A summary of the new GINA strategy: a roadmap to asthma control. Eur Respir J. 2015;46(3):622-39.

7. Chamieh MC, Moore HJ, SummerBell C, Tamim H, Sibai AM, Hwalla N. Diet, physical activity and socio-economic disparities of obesity in Lebanese adults: findings from a national study. BMC Public Health. 2015;15:279.

8. Taylor B, Mannino D, Brown C, Crocker D, Twum-Baah N, Holguin F. Body mass index and asthma severity in the national asthma survey. Thorax. 2008 ; 63:14-20.

9. Zarka A, Ulrik CS. Obesity and asthma: a coincidence or a causal relationship? A systematic review. Respir Med. 2013;107:1287-300.

10. Nguyen K, Zahran H, lqbal S, Peng J, Boulay E. Factors associated with asthma control among adults in five New England states, 2006-2007. J Asthma. 2011;48:581-8.

11. http://www.cdc.gov/obesity/downloads/BMlforPactitioners.pdf

12. Thomas M, Kay S, Pike J, Williams A, Rosenzweig J, Hillyer EV Prie D. Asthma Control Test (ACT) as a predictor of GINA guideline-defined asthma control: analysis of a multinational cross-sectional survey," Primary Care Respiratory Journal, 2009;18(1): 41-49.

13. Lababidi H, Hijaoui A, Zarzour Z. Validation of the Arabic version of the asthma control test. Annals of Thoracic Medicine. 2008;3:44-7.

14. Schatz M, Sorkness CA, Li JT, Marcus P, Murray JJ, Nathan RA, et al. Asthma control test: reliability, validity, and responsiveness in patients not previously followed by asthma specialists. J Allergy Clin Immunol. 2006;117(3):549-56.

15. Tantisira KG, Weiss ST. Complex interactions in complex traits: obesity and asthma. Thorax. 2001;56(SII:61-74.

16. Kanter R, Callabero B. Global Gender disparities in Obesity: A review. Adv Nutr. 2012;3:491-8

17. Nasreddine L, Naja F, Chamieh MC, Adra N, Sibai A-M, Hwalla N. Trends in overweight and obesity in Lebanon: evidence from two national crosssectional surveys (1997 and 2009). BMC Public Health. 2012;12:798. https:// doi.org/10.1186/1471-2458-12-798.

18. Cohen AK, Rai M, Rehkopf DH, Abrams B. Educational attainment and obesity: a systematic review. Obes Rev. 2013;14(12):989-1005.

19. Boulet L-P, FitzGerald JM, Mclvor RA, Zimmerman S, Chapman KR. Influence of current or former smoking on asthma management and control. Can Respir J. 2008;15(5):275-9.

20. Irani C, Nahas O, Saliba J. The effect of parental smoking on the severity of asthma in children: a cross-sectional study. Global J Health Sci. 2018;10(1).

21. Williams L, Joseph C, Peterson E, Wells K, Wang M, Chowdhry V, et al. Patients with asthma who do not fill their inhaled corticosteroids: a study of primary non-adherence. Journal All Clin Immunol. 2007;120(5):1153-9.
22. Lindsay J, Heaney L. Nonadherence in difficult asthma - facts, myths, and a time to act. Patient Prefer Adherence. 2013;7:329-36.

\section{Publisher's Note}

Springer Nature remains neutral with regard to jurisdictional claims in published maps and institutional affiliations.

\section{Ready to submit your research? Choose BMC and benefit from:}

- fast, convenient online submission

- thorough peer review by experienced researchers in your field

- rapid publication on acceptance

- support for research data, including large and complex data types

- gold Open Access which fosters wider collaboration and increased citations

- maximum visibility for your research: over $100 \mathrm{M}$ website views per year

At BMC, research is always in progress.

Learn more biomedcentral.com/submissions 